\title{
Diffusion Tensor Imaging of the Corpus Callosum in Addiction
}

\author{
Danilo Arnone $^{a, c}$ Mohammed T. Abou-Saleh ${ }^{a}$ Thomas R. Barrick \\ a Division of Mental Health and ${ }^{\mathrm{b} C e n t r e}$ for Clinical Neuroscience, Division of Cardiac and Vascular Sciences, \\ St. George's University of London, London, and 'Department of Psychiatry, University of Oxford, \\ Warneford Hospital, Oxford, UK
}

\section{Key Words}

Corpus callosum $\cdot$ Diffusion tensor imaging $\cdot$ Addictions

\begin{abstract}
Diffusion tensor imaging, a novel technique with an increased capability of detecting abnormalities in the white matter, has increasingly been employed in the study of the biology of addictions. A comprehensive search from a range of databases was conducted and publications on this topic were selected. Nine reports, eight published and one unpublished, met criteria for inclusion, five on alcoholism, three on cannabis and one on cocaine use. Findings of this review suggest focal disruption of commissural connectivity in the corpus callosum. In alcoholism, the genu and splenium were particularly affected with a different pattern in men and women, and an association with age and duration of substance use. In cocaine dependence, the genu and rostral body showed significant damage. Cannabis consumption may be associated with white matter disruption, but there is not sufficient evidence to support pathological changes in the corpus callosum. The improved detection of white matter pathology with diffusion tensor imaging supports the importance of future research in this field.
\end{abstract}

Copyright $\odot 2006$ S. Karger AG, Basel

\section{Introduction}

Interest in the corpus callosum (CC) in addictions began in 1985 with post-mortem neuropathological studies of patients with alcohol dependence (AD) consistently showing volumetric reduction in the white matter [1]. Most MRI studies have also confirmed white matter volume reduction in patients with $\mathrm{AD}$ although restricted to gross estimations. However, less is known about the mechanisms of alcohol-related volume loss and its functional significance $[2,3]$, nor are the mechanisms underlying volume restoration observed in alcohol abstinence $[2,4]$ clear. There is also controversy over the effect of gender and advancing age on white matter pathology in alcoholism [5, 6]. Neuropathology is even more uncertain in other types of substance misuse [7]. Voxel-based morphometrystudies support the hypothesis that MDMA (Ecstasy) users show reduction in cortical grey matter concentration in multiple brain regions including neocortex, brainstem, cerebellum, and anterior cingulate gyrus [8], which may translate into white matter abnormalities characterised by 'pruning' of serotoninergic neurons [9]. In cocaine users volumetric changes have been demonstrated [10] and white matter deficiencies could derive from 'perfusion defects' attributable to long-lasting alter-

\section{KARGER \\ Fax +41613061234 E-Mail karger@karger.ch} www.karger.com
Danilo Arnone, MD, DipCBT, MRCPsych

Department of Psychological Medicine

6th Floor Hunter Wing, St. George's University of London

Cranmer Terrace SW17 0RE (UK)

Tel. +44 208725 0368, Fax +44 208725 2914, E-Mail danilo.arnone@psych.ox.ac.uk 
ations in cerebral blood flow, enduring alterations in cerebral glucose metabolism persisting after cocaine discontinuation or neurotoxicity to brain dopamine neurons [11]. In chronic cannabis users, although there are signs of mild cognitive impairment, there is little evidence that such impairments are accompanied by druginduced neuropathology [12]. Diffusion tensor imaging (DTI) is a novel, non-invasive magnetic resonance technique capable of providing a more sensitive detection of white matter pathology. DTI quantifies in vivo the directionality and coherence of white matter fibre tracts [13] by detecting the freedom with which water molecules move within a tissue type and the amount and predominant intravoxel orientation of their diffusion [14]. Mean diffusivity (MD), a measure computed from DTI, quantifies the magnitude of (isotropic) water diffusivity in each image voxel and increases when boundaries to water diffusion are reduced. In particular, increased MD has been reported in lesions attributable to different neuropsychiatric conditions which may reflect oedema, demyelination, and axonal loss [15]. Fractional anisotropy (FA) is a further measure computed from DTI and quantifies how restricted (anisotropic) water diffusion is in each image voxel. Specifically, restrictions to water diffusion are caused by tissue microstructure, with a reduction in FA indicating a decline in tissue structural integrity. Finally, as DTI also provides a direction of predominant intravoxel orientation that corresponds to gross tissue orientation, the intervoxel coherence (IC) may be computed. This measure determines the coherence of local intravoxel diffusion orientations such that if local orientations are similar the IC is greater, with a reduced IC possibly providing evidence of disruption in tract organisation.

In summary, increased MD, reduced FA and reduced IC provide evidence of structural damage and may reflect a disruption in the organization of tracts [16]. These complementary measures are considered to be sensitive indices of axonal integrity [17]. For these reasons, a review of published data on CC volume in addictions was carried out. The CC was chosen because of its functional significance [18] and it is a large enough structure to allow reliable identification with region- of- interest methods. The aims of this review were (1) to establish whether DTI studies support current knowledge about volumetric changes in CC in alcoholism, (2) to clarify the role of ethanol-induced damage with reference to mechanisms of action, age, gender differences, lifetime alcohol consumption, time since last use, and (3) to determine the capability of DTI in detecting abnormalities in CC in other substance users.

\section{Methods}

A comprehensive search from a range of electronic databases, including BNI, CancerLit, Cochrane Library, EMBASE, Medline, Psychinfo, and PubMed was conducted for the period from the introduction of DTI to July 2006. Key words used to identify the studies were: diffusion tensor imaging, magnetic resonance imaging, DTI, RMI, alcoholism, marijuana, cannabis, cocaine, Ecstasy, MDMA, methamphetamine, and substance misuse. The search was also complemented by a manual search of bibliographic cross-referencing. Researchers who had expressed an interest in the subject were contacted for any non-published information. Papers were included if they presented original data and addressed the question, 'use of DTI in substance misuse'. Studies were screened for diagnosis according to ICD-10 or DSM-IV, inclusion/exclusion criteria, demographic variables (e.g. age, gender), clinical settings, length of exposure to substance of abuse, length of abstinence prior to scanning, presence of physical illness and co-morbid psychiatric illness. Studies with results that did not reach statistical significance or reported results for areas other than the CC were excluded.

\section{Results}

Eight published and one unpublished reports met criteria for inclusion (table 1), five on alcoholism [19-23], one on cocaine use [24] and three on cannabis [25-27]. One study by Lim et al. [28] was excluded because it did not include the CC. The studies were all case-control comparisons. Meta-analytic evaluation was not possible because group differences were presented in a form not amenable to effect size calculation. Details of the reports are given below.

\section{Alcohol Dependence}

All the studies [19-23] had a similar design: patients recruited were chronic users with a large consumption of ethanol assessed with semi-structured alcohol consumption assessment interviews and were abstinent prior to scanning; caseness was identified with structured clinical interviewer tools and diagnosis of $\mathrm{AD}$ was given according to standard diagnostic criteria; major mental and physical illnesses were excluded; confounding variables were minimised by assessing pre-morbid IQ, analysing gender-related data separately, excluding other substance misuse, and matching for age. Only one study matched for handedness [22], and another for body mass index [23]. Pfefferbaum et al. [19] recruited 15 alcoholic men and 19 controls. CC volume showed lower FA in the alcoholic group in the genu $(\mathrm{p}<0.05)$ with a significant correlation with time from last drink $(\mathrm{p}<0.001)$ but not age $(p>0.05)$. IC failed to yield significant group or interac- 
Table 1. Studies of corpus callosum in addiction

\begin{tabular}{|c|c|c|c|c|c|c|c|c|}
\hline \multirow[t]{2}{*}{ Study name } & \multicolumn{4}{|l|}{ Cases } & \multicolumn{3}{|l|}{ Controls } & \multirow[t]{2}{*}{ Findings } \\
\hline & $\begin{array}{l}\text { mean consumption/ } \\
\text { duration of use }\end{array}$ & $\begin{array}{l}\text { abstinence } \\
\text { days }\end{array}$ & $\begin{array}{l}\mathrm{n} \\
(\mathrm{m} / \mathrm{f})\end{array}$ & $\begin{array}{l}\text { mean age } \\
\text { years }\end{array}$ & $\begin{array}{l}\text { mean } \\
\text { consumption }\end{array}$ & $\begin{array}{l}\mathrm{n} \\
(\mathrm{m} / \mathrm{f})\end{array}$ & $\begin{array}{l}\text { mean age } \\
\text { years }\end{array}$ & \\
\hline $\begin{array}{l}\text { Pfefferbaum } \\
\text { et al. [19] }\end{array}$ & $1,484.6 \mathrm{~kg}$ & 332 & $15 / 0$ & 55.4 & $65.9 \mathrm{~kg}$ & $19 / 0$ & 54.4 & $\downarrow \mathrm{FA}$ in $\mathrm{G}(\mathrm{p}<0.05)$ \\
\hline \multirow{2}{*}{$\begin{array}{l}\text { Pfefferbaum } \\
\text { and Sullivan [20] }\end{array}$} & $\mathrm{m}: \quad 301 \mathrm{~kg}$ & 322 & \multirow[t]{2}{*}{$15 / 12$} & $\mathrm{~m}: 55.4$ & $\mathrm{~m}: 65.9 \mathrm{~kg}$ & \multirow[t]{2}{*}{$31 / 18$} & $\mathrm{~m}: 44.7$ & \multirow{2}{*}{$\begin{aligned} \mathrm{f}: & \downarrow \mathrm{FA} \text { in } \mathrm{G}(\mathrm{p}<0.05) \\
& \downarrow \mathrm{IC} \text { in } \mathrm{G}(\mathrm{p} \leq 0.02) \\
\mathrm{m}: & \downarrow \mathrm{FA} \text { in } \mathrm{G}(\mathrm{p}<0.05) \\
& \text { and } \mathrm{S}(\mathrm{p}<0.05) \\
& \downarrow \mathrm{IC} \text { in } \mathrm{S}(\mathrm{p}=0.0001)\end{aligned}$} \\
\hline & f: $\quad 1,484.6 \mathrm{~kg}$ & 677 & & $\mathrm{f}: 45.8$ & f: $\quad 13.3 \mathrm{~kg}$ & & f: 43.8 & \\
\hline $\begin{array}{l}\text { Pfefferbaum and } \\
\text { Sullivan [21] }\end{array}$ & $1,484.6 \mathrm{~kg}$ & 322 & $15 / 0$ & 55.4 & $65.9 \mathrm{~kg}$ & $19 / 0$ & 54.4 & $\begin{array}{l}\uparrow M D \text { in } C C(p=0.0698) \\
\downarrow F A \text { in } C C(p<0.05)\end{array}$ \\
\hline Schulte et al. [22] & $511.3 \mathrm{~kg}$ & NS & $7 / 4$ & 42.6 & $48.5 \mathrm{~kg}$ & $8 / 5$ & 51.6 & $\begin{array}{l}\downarrow F A \text { in } C C(p<0.03) \\
\uparrow M D \text { in } C C(p<0.005)\end{array}$ \\
\hline Pfefferbaum et al. [23] & $\begin{array}{l}\text { m: } 1,032.8 \mathrm{~kg} \\
\mathrm{f:} \quad 411.5 \mathrm{~kg}\end{array}$ & NS & $40 / 17$ & $\begin{array}{l}\mathrm{m}: 52.8 \\
\mathrm{f:} \quad 50.4\end{array}$ & $\begin{array}{l}\mathrm{m}: 66.6 \mathrm{~kg} \\
\mathrm{f:} \quad 32.2 \mathrm{~kg}\end{array}$ & $32 / 42$ & $\begin{array}{l}\mathrm{m}: 52.2 \\
\mathrm{f:} \quad 54.4\end{array}$ & $\begin{array}{l}\downarrow F A \text { in } \mathrm{CC}(\mathrm{p}<0.001) \\
(\mathrm{men}>\text { women }), \\
\uparrow \mathrm{MD} \text { in } \mathrm{CC}(\mathrm{p}<0.0008)\end{array}$ \\
\hline Moeller et al. [24] & 9.7 years & NS & $14 / 4$ & 33.1 & nil & $14 / 4$ & 26.2 & $\downarrow \mathrm{FA}$ in $\mathrm{CC}(\mathrm{p}<0.007)$ \\
\hline $\begin{array}{l}\text { Gruber and Yurgelun- } \\
\text { Todd [25] }\end{array}$ & $\begin{array}{l}\text { age of onset } 14.1 \text { years, } \\
\geq 4,000 \text { times }\end{array}$ & $\begin{array}{l}\text { currently } \\
\text { using }\end{array}$ & $8 / 1$ & 26.8 & nil & $8 / 1$ & 26.2 & $\uparrow \downarrow F A$ in $\mathrm{CC}$ \\
\hline DeLisi et al. [26] & $\begin{array}{l}\text { not current use, } \\
\geq 1 \text { year of use when } \\
\text { aged } \leq 18\end{array}$ & NS & $9 / 1$ & 21.1 & nil & $9 / 1$ & 23.0 & $\uparrow \downarrow F A$ in CC \\
\hline Arnone et al. [27] & $\begin{array}{l}8.6 \text { years duration, } \\
\text { mean first use } \\
\text { aged } 15.3 \text { years }\end{array}$ & $\begin{array}{l}\text { currently } \\
\text { using } \\
\text { (daily) }\end{array}$ & 11 & 25.0 & nil & 11 & 23.0 & 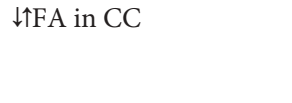 \\
\hline
\end{tabular}

$\mathrm{G}=\mathrm{Genu} ; \mathrm{S}$ = splenium; NS = not specified.

tion effects. Pfefferbaum and Sullivan [20] examined 27 subjects ( 12 women and 15 men) in comparison to 49 controls ( 31 men and 18 women). Both alcoholic women and men showed significantly lower FA in the genu $(\mathrm{p}<0.05)$, but only men in the splenium $(\mathrm{p}<0.05)$. IC was significantly decreased in the alcoholic women in the genu $(\mathrm{p} \leq 0.02)$ and in the splenium in alcoholic men ( $\mathrm{p}=$ 0.0001 ). Lifetime alcohol consumption was inversely correlated to genu area $(\mathrm{p}=0.02)$ and genu FA $(\mathrm{p}=0.02)$. Pfefferbaum and Sullivan [21] examined 15 alcoholic men and 19 controls. Alcoholics had abnormally high white matter MD in the genu ( $p=0.0698)$, which inversely correlated with FA $(\mathrm{p}<0.05)$. Total lifetime consumption of alcohol did not correlate with diffusivity. The correlation between $\mathrm{MD} / \mathrm{FA}$ and age in the patients with $\mathrm{AD}$ was also significant $(p<0.05)$. Schulte et al. [22] examined 11 patients with $\mathrm{AD}$ (7 men and 4 women) and 13 controls ( 8 men and 5 women). FA was lower in alcoholics in CC $(p=0.03)$. Also in the patients with AD lifetime alcohol intake correlated positively with $\mathrm{MD}$ and negatively with FA in the total CC ( $\mathrm{p}=0.005$ and 0.01 , respectively). Pfefferbaum et al. [23] studied 57 alcoholics (40 men and 17 women) and 74 controls ( 32 men and 42 women). Both alcoholic men and women had FA deficits in the all CC ( $\mathrm{p}=0.0001)$ with lower FA in alcoholic men compared to women. MD was higher in both alcoholic groups in the all CC ( $<0.0008)$. Correlational analyses revealed that in the alcoholic groups, the smaller the CC, the lower the FA and the higher the MD. The genu was the CC area more affected $(\mathrm{p}<0.009)$. Advancing age predicted smaller callosal area, lower FA, higher MD in the CC of the all alcoholic group ( $\mathrm{p}=0.018$ and 0.0003 , respectively) and alcoholic men $(\mathrm{p}<0.026$ and 0.0007 , respectively), but not in alcoholic women ( $p>0.05)$. The genu and splenium areas were generally more affected. In the men, greater lifetime alcohol consumption correlated with smaller splenium area $(\mathrm{p}=0.02)$. 


\section{Cocaine Dependence}

Moeller et al. [24] studied 18 cocaine-dependent subjects and 18 healthy controls (14 men and 4 women in each group). All subjects were screened for medical disorders, psychiatric illness and severity of drug use using structured interviews. Results of the DTI showed significantly reduced FA in the genu $(\mathrm{p}=0.007)$ and rostral body ( $\mathrm{p}=0.004)$ of the anterior CC in cases. The initially significant negative correlation between FA in the genu and years of self-reported cocaine use $(p=0.03)$ and years of alcohol use $(\mathrm{p}=0.007)$ lost its significance when controlled for age $(p>0.05)$. Controlling for use of amphetamines did not affect results $(\mathrm{p}>0.05)$.

\section{Cannabis Use}

Gruber and Yurgelun-Todd [25] compared 9 cannabis users ( 8 male and 1 female) with 9 healthy matched controls. Psychopathology was excluded by using standardised criteria. Medical conditions and current use of other substances than marijuana were excluded. Users were selected on the basis of lifetime consumption of cannabis ( $\geq 4,000$ times) and positive urine test to cannabinoids. The study aimed to elicit possible abnormalities detectable with functional MRI in executive functions with the use of the Stroop test. Also DTI analysis was performed as an adjunct. DTI results showed no difference in FA in the CC between cases and controls but a trend towards an increased trace in marijuana smokers $(\mathrm{p}=$ 0.09). DeLisi et al. [26] studied 10 subjects (9 female and 1 male) who used cannabis during their adolescence ( $\leq 18$ years) for $\geq 1$ years between $2-7$ times a week ( $>21$ times/ year) and 10 healthy controls matched for sex and age and social class. All 10 cases were non-users at the time of scanning. Three cases also used other illegal drugs in the past and were frequent alcohol consumers. All subjects were selected according to diagnostic interviews and mental illness was excluded. Results of the DTI did not show significantly reduced FA in the CC in adolescent cannabis users but FA was increased in the left anterior cingulate, right medial frontal gyrus, left precentral gyrus, right inferior parietal, right cingulated gyrus and left superior frontal gyrus $\left(\mathrm{p}<0.01\right.$, cluster size $\left.>200 \mathrm{~mm}^{3}\right)$. The authors concluded that findings did not support pathological changes in the white matter of individuals who used marijuana at least moderately during adolescence. Arnone et al. [27] studied 11 male, right-handed, heavy cannabis users with a 'whole brain' approach. Subjects were well matched for gender, age, handedness, and other substances, including alcohol, were controlled for. Strict exclusion criteria included physical and mental ill- ness. To measure whole brain white matter structural integrity, a histogram analysis was used. In marijuana users, median FA was decreased in comparison with controls $(\mathrm{p}=0.03)$. Preliminary findings using regionof-interest analysis in the whole CC did not find statistical difference between cases and controls $(p>0.05)$. These preliminary results do not support the possibility of white matter damage in the CC of heavy cannabis users but further analysis is currently underway.

\section{Discussion}

\section{CC in Chronic Alcoholism}

Neuropathology. DTI results across the studies confirmed white matter pathology in the CC [19-23]. Consistent findings were a reduction in FA and IC in the CC and more significantly in the genu and the splenium (genu $>$ splenium). Studies which also considered MD reported increased values in alcoholics with a negative correlation between MD and FA particularly in the genu [21-23]. The genu and the splenium connect left and right frontal sites and parietal and occipital sites, respectively [29]. These observations are in agreement with white matter shrinkage reported in post-mortem [30] and MRI [31] studies. It is therefore possible that DTI changes in genu and splenium result from compromised primary directionality of fibres in these areas which can be caused by oedema, demyelination, and axonal loss [16]. Animal models of stroke postulated that a strong negative correlation between FA and MD would support extracellular white matter damage; conversely a less strong correlation would be in keeping with intracellular damage [31]. In this context, white matter disruption in the genu of the CC would be commonly a consequence of extracellular pathology, e.g. oedema, whereas the splenium could be damaged by intracellular cytoskeletal damage. The latter would be in agreement with down-regulation of genes responsible for cytoskeletal proteins as observed in animals [32].

Gender Differences. Women alcoholics showed decreased FA [20,23], IC [20] and a higher MD [23] in the CC compared to controls particularly in the genu [20]. Compared to men, women alcoholics showed no involvement of the splenium of the CC $[20,23]$. These findings suggest that the degree of white matter abnormality in the CC may be present in wider regions of the CC and that in women alcoholics it is likely to be less pronounced compared to men and possibly more difficult to detect with conventional MRI techniques. Sex differences in axonal 
density have been described in some areas of the CC [33]. The genu in women may be more prone to focal damage and therefore detectable with DTI. Differences could also be explained by a number of other variables not controlled for, e.g. different magnitude of lifetime alcohol consumption in women, younger age, and possible differences in the metabolism of alcohol.

Lifetime Alcohol Consumption. Lifetime alcohol consumption generally correlated positively with $\mathrm{MD}$, and negatively with FA and C [20, 22, 23].

Time to Last Drink. One study reported a significant positive correlation between genu FA and time to last drink [19]. This finding underlies a possible acute toxic effect of alcohol which may be detected with DTI rather than chronic changes. Another important effect which could account for this result is the documented increase in brain volume associated with abstinence capable of affecting MD and FA [34].

Effect of Age on Alcoholism. DTI showed that in the genu and splenium of the CC of older alcoholics had greater shrinkage for their age than did younger alcoholics [21-23]. As reported elsewhere [35], age is an independent variable correlated with a natural decline in FA and enhanced MD in normal subjects in the CC equally in men and women. This was observed in controls [e.g. ref. 22]. In alcoholic patients, age was positively correlated with alcoholism, suggesting that the combined effect of increasing age and chronic alcoholism can potentiate the effect of either alone, but also suggesting a greater effect of alcohol consumption over age in alcoholics on the disruption of brain white matter.

\section{CC in Cocaine Users}

Moeller et al. [24] found significantly lower FA in the genu and rostral body of the CC compared to controls. The initial negative correlation between FA in the genu and years of self-reported cocaine use/years of alcohol use lost its significance when age was controlled for. Although the authors controlled for the effect of amphetamine use, use of other substances was not controlled for and may have potentially affected the validity of their findings. Also, other variables, e.g. handedness and gender, were not considered in the analysis. With all these limitations, this study suggests reduced integrity of anterior CC white matter, supporting frontal cortical impairment in cocaine-dependent subjects.

\section{CC in Cannabis Users}

Gruber and Yurgelun-Todd [25] published the first study using DTI in cannabis users which showed no dif- ferences between cases and controls in FA in the CC. There was a trend towards increased FA in the CC suggestive of the effect of possible confounders. Alternatively, since the study aimed to show a possible derailment in executive functions in cannabis users with $\mathrm{fMRI}$, it might have suffered the limitations of a non-ideal design or underpower. DeLisi et al. [26] did not find significant differences in FA in the CC of subjects who used marijuana during their adolescent years. Some users also consumed significant quantities of alcohol and other substances potentially able to affect the overall results. Subjects were only mild to moderate users and it was not possible to control for physical and psychiatric co-morbidity. It is arguable that based on the time lapsed from the last use to DTI scanning, at least some of the neurotoxic effect of cannabis might have recovered. A cluster size of $>200 \mathrm{~mm}^{3}$ might have significantly introduced sufficient background noise to justify the detection of an increased FA in some brain regions. Arnone et al. [27] did not find decreased FA in the CC despite encouraging evidence using a whole brain histogram approach. If confirmed with further analysis, this finding is suggestive of the fact that the magnitude of white matter damage in the CC of heavy cannabis users could be small if present at all. This study not only included subjects who were current users but also targeted individuals who began to use marijuana during their adolescence, the most sensitive neurodevelopmental phase to neuroplastic changes.

\section{Implications for Further Studies}

DTI shows good potential for improved detection of white matter pathology in vivo which antecedes gross morphological changes identifiable with conventional MRI techniques. However, it is conceivable that these studies did not have enough power to detect consistent results as shown by the modest number of subjects included in these reports (table 1). In chronic alcoholism the majority of the studies were published by the same group (table 1). The main shortcoming of this observation is the overall decreased generalisability of the results. Most of the studies attempted matching at least for age when IQ, gender, education, polysubstance use, and handedness are all capable of affecting FA parameters [36] and were not always controlled for. Patient samples might have been different with respect to the severity and duration of addiction, variation in length of abstinence. There may also be some differences in DTI methodology and only very few studies used 'optimised' gradient schemes [e.g. ref. 23]. All the studies adopted a region-ofinterest approach. Although this is an acceptable ap- 
proach, the demarcation of the regions selected is subjective; this should be guided by unambiguous criteria and with demonstrated interrater/intrarater reliability. The risk of a systematic placement bias was minimised by choosing a very identifiable region like the CC. Effect size is difficult to assess because DTI is a novel technique and still under experimentation. Future research could employ larger, homogeneous patient groups selected according to clearly defined diagnostic criteria, whose substance use could be quantified with validated scales. The time from last use of the substance to time of scanning may potentially be crucial in differentiating acute from longer-lasting changes and should be controlled for. A whole brain approach may prevent occurrence of systematic bias but would probably require a larger sample size. To further clarify the mechanisms of white matter damage, its possible reversibility, and to exclude/confirm illness progression, DTI could be employed in longitudinal studies to show modification of neuropathological findings during different stages of dependence (current use/abstinence/relapse). This would also allow the study of the ef- fectiveness of treatment in ameliorating white matter integrity like, for instance, adequate nutrition, vitamin supplementation, and pharmacological treatment.

\section{Conclusion}

In patients with $\mathrm{AD}, \mathrm{DTI}$ showed white matter abnormalities in the CC consistent with compromised primary directionality of fibres. A regional pattern was reported with genu and the splenium particularly affected. Women appeared less vulnerable to white matter disruption. The effect of alcohol was amplified by increasing age and longer lifetime consumption. Time to last drink and length of abstinence prior to scanning demonstrated potentials for affecting results. In cocaine dependence, results showed reduced FA in the genu and rostral body of the CC which lost significance when age was controlled for. There is not sufficient evidence to support white matter damage in the $\mathrm{CC}$ of marijuana users.

\section{References}

1 Harper C: The neuropathology of alcoholspecific brain damage, or does alcohol damage the brain? J Neuropathol Exp Neurol 1998;57:101-110.

-2 Lewohl J, Wang L, Miles M, Zhang L, Dodd $P$, Harris R: Gene expression in human alcoholism: microarray analysis of frontal cortex. Alcohol Clin Exp Res 2000;24:18731882.

- 3 Harper CG, Krill JJ, Daly JM: Are we drinking our neurones away? BMJ 1987;294:534536.

4 Harper C, Matsumoto I: Ethanol and brain damage. Curr Opin Pharmacol 2005;5:7378.

$\checkmark 5$ Pfefferbaum A, Lim KO, Zipursky RB, Mathalon $\mathrm{DH}$, Lane $\mathrm{B}, \mathrm{Ha} \mathrm{CN}$, et al: Brain gray and white matter volume loss accelerates with aging in chronic alcoholics: a quantitative MRI study. Alcohol Clin Exp Res 1992; 16:1078-1089.

-6 Hommer D, Momenan R, Rawlings R, Ragan P, Williams W, Rio D, Eckardt M: Decreased corpus callosum size among alcoholic women. Arch Neurol 1996;53:359-363.

7 Schlaepfer TE, Lancaster E, Heidbreder R, Strain EC, Kosel M, Fisch HU, Pearlson GD: Decreased frontal white-matter volume in chronic substance abuse. Int J Neuropsychopharmacol 2005;8:1-7.
Cowan RL, Lyoo IK, Sung SM, Ahn KH, Kim MJ, Hwang J, Haga E, Vimal RLP, Lukas SE, Renshaw PF: Reduced cortical gray matter density in human MDMA (Ecstasy) users: a vokel-based morphometry study. Drug Alcohol Depend 2003;72:225-235.

-9 Ricaurte GA, Yuan J, McCann UD: (+/-)3,4Methylenedioxymethamphetamine ('Ecstasy')-induced serotonin neurotoxicity: studies in animals. Neuropsychobiology 2000; 42:5-10.

10 Pascual-Leone A, Dhuna A, Anderson DC: Cerebral atrophy in habitual cocaine abusers: a planimetric CT study. Neurology 1991; 41:34-38.

11 Nnadi CU, Mimico OA, McCurtic HL, Cadet JL: Neuropsychiatric effects of cocaine use disorders. J Natl Med Assoc 2005;97:15041515.

12 Iversen L: Cannabis and the brain. Brain 2003; 126:1252-1270.

$\checkmark 13$ Beaulieu C: The basis of anisotropic water diffusion in the nervous system: a technical review. NMR Biomed 2002;15:435-455.

14 Rosenbloom M, Sullivan EV, Pfefferbaum A: Using magnetic resonance imaging and diffusion tensor Imaging to assess brain damage in alcoholics. Alcohol Res Health 2003; 27:146-152.

15 Lim KO, Helpern JA: Neuropsychiatric applications of DTI: a review. NMR Biomed 2002;15:587-593.
16 Werring DJ, Clark CA, Barker GJ: The structural properties of multiple sclerosis lesions demonstrated by diffusion tensor imaging. ISMRM 1998;119.

17 Foong J, Maier M, Clark CA, Barker GJ, Miller DH, Ron MA: Neuropathological abnormalities of the corpus callosum in schizophrenia: a diffusion tensor imaging study. J Neurol Neurosurg Psychiatry 2000;68:242244.

18 Pfefferbaum A, Sullivan EV: Increased brain white matter diffusivity in normal adult aging: relationship to anisotropy and partial voluming. Magn Reson Med 2003;49:953961.

19 Pfefferbaum A, Sullivan EV, Hedehus M, Adalsteinsson E, Lim KO, Moseley M: In vivo detection and functional correlates of white matter microstructural disruption in chronic alcoholism. Alcohol Clin Exp Res 2000;24:1214-1221.

20 Pfefferbaum A, Sullivan EV: Microstructural but not macrostructural disruption of white matter in women with chronic alcoholism. Neuroimage 2002;15:708-718.

21 Pfefferbaum A, Sullivan EV: Disruption of brain white matter microstructure by excessive intracellular and extracellular fluid in alcoholism: evidence from diffusion tensor imaging. Neuropsychopharmacology 2005; 30:423-432. 
-22 Schulte T, Sullivan EV, Muller-Oehring EM, Adalsteinsson E, Pfefferbaum A: Corpus callosal microstructural integrity influences interhemispheric processing: a diffusion tensor imaging study. Cereb Cortex 2005; 15 : 1384-92.

-23 Pfefferbaum A, Adalsteinsson E, Sullivan EV: Dysmorphology and microstructural degradation of the corpus callosum: interaction of age and alcoholism. Neurobiol Aging 2006;27:994-1009.

-24 Moeller FG, Hasan KM, Steinberg JL, Kramer LA, Dougherty DM, Santos RM, et al: Reduced anterior corpus callosum white matter integrity is related to increased impulsivity and reduced discriminability in cocaine-dependent subjects: diffusion tensor imaging. Neuropsychopharmacology 2005;30:610-617.

-25 Gruber SA, Yurgelun-Todd DA: Neuroimaging of marijuana smokers during inhibitory processing: a pilot investigation. Cogn Brain Res 2005;23:107-118.

26 DeLisi LE, Bertisch HC, Szulc KU, Majcher M, Brown K, Bappal A, Ardekani BAP: A preliminary DTI study showing no brain structural change associated with adolescent cannabis use. Harm Reduct J 2006;3:17.
27 Arnone D, Chengappa S, Barrick TR, Hynes J, Govender R, Clark C, Abou-Saleh MT: White matter neuropathological correlates of chronic marijuana use: a diffusion tensor imaging study. J Psychopharmacol 2006;20: A57.

28 Lim KO, Choi SJ, Pomara N, Wolkin A, Rotrosen JP: Reduced frontal white matter integrity in cocaine dependence: a controlled diffusion tensor imaging study. Biol Psychiatry 2002;51:890-895.

29 de Lacoste M, Kirkpatrick J, Ross E: Topography of the human corpus callosum. J Neuropathol Exp Neurol 1985;44:578-591.

30 De la Monte SM: Disproportionate atrophy of cerebral white matter in chronic alcoholics. Arch Neurol 1988;45:990-992.

- 31 Silva MD, Omae T, Helmer KG, Li F, Fisher $\mathrm{M}$, Sotak CH: Separating changes in the intra- and extracellular water apparent diffusion coefficient following focal cerebral ischemia in the rat brain. Magn Reson Med 2002; 48:826-837.

32 Putzke J, De Beun R, Schreiber R, De Vry J, Tolle T, Zieglgansberger W, et al: Long-term alcohol self-administration and alcoho withdrawal differentially modulate microtubule-associated protein 2 (MAP-2) gene expression in the rat brain. Brain Res Mol Brain Res 1998;62:196-205.
33 Highley JR, Esiri MM, McDonald B, Cortina-Borja $\mathrm{M}$, Herron BM, Crow TJ: The size and fibre composition of the corpus callosum with respect to gender and schizophrenia: a post-mortem study. Brain 1999;122: 99-110.

34 Parks MH, Dawant BM, Riddle WR, Hartmann SL: Longitudinal brain metabolic characterization of chronic alcoholics with proton magnetic resonance spectroscopy. Alcohol Clin Exp Res 2002;26:1368-1380.

35 Sullivan EV, Adalsteinsson E, Hedehus M, Ju C, Moseley M, Lim KO, Pfefferbaum A: Equivalent disruption of regional white matter microstructure in ageing healthy men and women. Neuroreport 2001;12:99-104.

-36 Westerhausen R, Walter C, Kreuder F, Wittling RA, Schweiger E, Wittling W: The influence of handedness and gender on the microstructure of the human corpus callosum: a diffusion-tensor magnetic resonance imaging study. Neurosci Lett 2003;351:99102. 